\title{
Exploring the nature of interprofessional collaboration and family member involvement in an intensive care context
}

Citation for published version (APA):

Paradis, E., Reeves, S., Leslie, M., Aboumatar, H., Chesluk, B., Clark, P. G., Courtney, M., Frank, L., Lamb, G., Lyndon, A., Mesman, J., Puntillo, K., Schmidt, M., van Soeren, M., Wachter, R. M., Zwarenstein, M., Gropper, M. A., \& Kitto, S. (2014). Exploring the nature of interprofessional collaboration and family member involvement in an intensive care context. Journal of Interprofessional Care, 28(1), 7475. https://doi.org/10.3109/13561820.2013.781141

Document status and date:

Published: 01/01/2014

DOI:

10.3109/13561820.2013.781141

Document Version:

Publisher's PDF, also known as Version of record

\section{Document license:}

Taverne

Please check the document version of this publication:

- A submitted manuscript is the version of the article upon submission and before peer-review. There can be important differences between the submitted version and the official published version of record.

People interested in the research are advised to contact the author for the final version of the publication, or visit the DOI to the publisher's website.

- The final author version and the galley proof are versions of the publication after peer review.

- The final published version features the final layout of the paper including the volume, issue and page numbers.

Link to publication

\footnotetext{
General rights rights.

- You may freely distribute the URL identifying the publication in the public portal. please follow below link for the End User Agreement:

www.umlib.nl/taverne-license

Take down policy

If you believe that this document breaches copyright please contact us at:

repository@maastrichtuniversity.nl

providing details and we will investigate your claim.
}

Copyright and moral rights for the publications made accessible in the public portal are retained by the authors and/or other copyright owners and it is a condition of accessing publications that users recognise and abide by the legal requirements associated with these

- Users may download and print one copy of any publication from the public portal for the purpose of private study or research.

- You may not further distribute the material or use it for any profit-making activity or commercial gain

If the publication is distributed under the terms of Article $25 f a$ of the Dutch Copyright Act, indicated by the "Taverne" license above, 


\section{Exploring the nature of interprofessional collaboration and family member involvement in an intensive care context}

Elise Paradis, Scott Reeves, Myles Leslie, Hanan Aboumatar, Ben Chesluk, Philip Clark, Molly Courtenay, Linda Franck, Gerri Lamb, Audrey Lyndon, Jessica Mesman, Kathleen Puntillo, Mattie Schmitt, Mary van Soeren, Bob Wachter, Merrick Zwarenstein, Michael Gropper \& Simon Kitto

To cite this article: Elise Paradis, Scott Reeves, Myles Leslie, Hanan Aboumatar, Ben Chesluk, Philip Clark, Molly Courtenay, Linda Franck, Gerri Lamb, Audrey Lyndon, Jessica Mesman, Kathleen Puntillo, Mattie Schmitt, Mary van Soeren, Bob Wachter, Merrick Zwarenstein, Michael Gropper \& Simon Kitto (2014) Exploring the nature of interprofessional collaboration and family member involvement in an intensive care context, Journal of Interprofessional Care, 28:1, 74-75, DOI: $10.3109 / 13561820.2013 .781141$

To link to this article: https://doi.org/10.3109/13561820.2013.781141

Published online: 14 May 2013.

Џll Article views: 1396

View Crossmark data ¿
Submit your article to this journal $\sqsubset$

Citing articles: 3 View citing articles 


\title{
Exploring the nature of interprofessional collaboration and family member involvement in an intensive care context
}

\author{
Elise Paradis ${ }^{1}$, Scott Reeves ${ }^{1}$, Myles Leslie ${ }^{2}$, Hanan Aboumatar ${ }^{2}$, Ben Chesluk ${ }^{3}$, Philip Clark ${ }^{4}$, Molly Courtenay ${ }^{5}$, \\ Linda Franck ${ }^{6}$, Gerri Lamb ${ }^{7}$, Audrey Lyndon ${ }^{6}$, Jessica Mesman ${ }^{8}$, Kathleen Puntillo ${ }^{9}$, Mattie Schmitt ${ }^{10}$, \\ Mary van Soeren ${ }^{11}$, Bob Wachter ${ }^{12}$, Merrick Zwarenstein ${ }^{13}$, Michael Gropper ${ }^{14}$ and Simon Kitto ${ }^{15}$ \\ ${ }^{1}$ Department of Social and Behavioral Sciences and Center for Innovation in Interprofessional Education, University of California, San Francisco, \\ USA, ${ }^{2}$ Armstrong Institute for Patient Safety and Quality, Johns Hopkins Medical Institutions, Baltimore, USA, ${ }^{3}$ American Board of Internal Medicine, \\ Philadelphia, USA, ${ }^{4}$ Human Science and Services, University of Rhode Island, Kingston, USA, ${ }^{5}$ Betty Irene Moore School of Nursing, University of \\ California, Davis, USA, ${ }^{6}$ Department of Family Health Care Nursing, University of California, San Francisco, USA, ${ }^{7}$ College of Nursing \& Health \\ Innovation, Arizona State University, Phoenix, USA, ${ }^{8}$ Faculty of Arts and Social Sciences, Maastricht University, The Netherlands, ${ }^{9}$ Physiological \\ Nursing, University of California, San Francisco, USA, ${ }^{10}$ School of Nursing, University of Rochester Medical Center, Rochester, USA, ${ }^{11}$ Canadian \\ Health Care Innovations, Guelph, Canada, ${ }^{12}$ School of Medicine, University of California, San Francisco, USA, ${ }^{13}$ Centre for Studies in Family \\ Medicine, University of Western Ontario, Canada, ${ }^{14}$ Anesthesia and Perioperative Care, University of California, San Francisco, USA, and \\ ${ }^{15}$ Department of Surgery, University of Toronto, Toronto, Ontario, Canada
}

\begin{abstract}
Little is known about the nature of interprofessional collaboration on intensive care units (ICUs), despite its recognition as a key component of patient safety and quality improvement initiatives. This comparative ethnographic study addresses this gap in knowledge and explores the different factors that influence collaborative work in the ICU. It aims to develop an empirically grounded team diagnostic tool, and associated interventions to strengthen teambased care and patient family involvement. This iterative study is comprised of three phases: a scoping review, a multi-site ethnographic study in eight ICUs over 2 years; and the development of a diagnostic tool and associated interprofessional intervention-development. This study's multi-site design and the richness and breadth of its data maximize its potential to improve clinical outcomes through an enhanced understanding of interprofessional dynamics and how patient family members in ICU settings are best included in care processes. Our research dissemination strategy, as well as the diagnostic tool and associated educational interventions developed from this study will help transfer the study's findings to other settings.
\end{abstract}

\section{Keywords}

Clinical outcomes, comparative, ethnography, intensive care, interprofessional collaboration, multi-site, patient involvement, teamwork

\section{History}

Received 5 December 2012

Revised 22 February 2013

Accepted 26 February 2013

Published online 14 May 2013

\section{Introduction}

Attempts to improve quality of care and patient safety in the ICU have seen mixed results (Bosk, Dixon-Woods, Goeschel, \& Pronovost, 2009; Pronovost, 2011), and some argue that this slow progress is partly due to the poor understanding of the contextual factors that impact health care delivery (Stevens \& Shojania, 2011). Consideration of these factors using qualitative research methods may be the next step in improving interprofessional dynamics and health outcomes in the ICU (e.g. Sinuff, Cook, \& Giacomini, 2007).

Previous ethnographic studies of teamwork in health care typically focused on intraprofessional dynamics at a single site and excluded patients and families from the analysis (Reeves, Lewin, Espin, \& Zwarenstein, 2010), limiting their transferability and usefulness to ICU personnel, managers, patients and families.

Correspondence: Scott Reeves, PhD., Center for Innovation in Interprofessional Education, University of California, San Francisco 530 Parnassus Avenue, CL112, San Francisco, CA 94131, USA. Tel: 415476 5134 (work); 4156022494 (home). Fax: 415476 9690. E-mail: Scott.Reeves@ucsf.edu
This study will employ a comparative ethnographic approach: the systematic and careful observation, documentation and analysis of the behaviors and attitudes across several groups or cultures (Rohner, 1977) across several sites. It will build on work by Reeves et al. (2010) to investigate the factors that impact interprofessional care delivery. Comparative ethnography highlights similarities and differences in the meanings and functions of human actions and beliefs, and is particularly suited for the development of diagnostic tools and interventions that consider cultural variation.

\section{Methods}

Our study has three goals. First, to comprehensively explore, through the use of ethnographic methods, the collaborative cultures of six ICUs in hospital sites in the US and two ICUS in Canada. Second, based on this rich ethnographic work, to identify an empirically-based diagnostic tool that can indicate whether optimal collaborative team-based care is being delivered. Third, to develop iteratively a set of ICU interventions that focuses on strengthening interprofessional collaboration and family member involvement in both care delivery and care decision-making. 
This study is divided into three main phases: a scoping review of the qualitative literature on team dynamics in the ICU; data collection across eight different medical/surgical intensive care units across the US and Canada; and instrument and intervention development to improve interprofessional collaboration and family member involvement in the ICU. It is iterative in nature: findings from earlier stages in the study will inform future steps, as is common and recommended in qualitative research (Reeves, Kuper, \& Hodges, 2008).

Phase 1 of the project will involve a scoping review that will answer the question: what do we know about interprofessional care in the ICU from published qualitative research? Recent ethnographic studies on interprofessional dynamics through searches of the PubMed/Medline, CINAHL and Scopus databases will be gathered to provide an insight into this area.

Phase 2 will consist of an on-site research, using four trained ethnographers in eight sites across North America. Approval will be obtained from the human subject review boards at each of the participating institutions. The study will gather ethnographic data as well as quantitative data for each ICU to examine (1) the processes of interprofessional collaboration and family member involvement, as well as (2) the clinical outcomes each unit generates. Qualitative data collection will include observations, informal and formal interviews of ICU professionals and family members. Documents such as patient and family brochures, care protocols, etc., will also be collected when pertinent, along with unit-level outcomes data on patient length of stays, unplanned readmissions, complication rates, infection rates, error rates (medical errors, adverse drug reactions, near misses) and family outcomes (satisfaction, stress levels).

In Phase 3 of the study, the research team and a study advisory group will develop a diagnostic tool that will be used to assess the levels of both interprofessional collaboration, and family caregiver involvement in the ICU. It is anticipated that this tool will consist of a range of elements (e.g. observation checklists, structured interviews) that will need to be triangulated to help generate a rapid, but accurate account of the current state of local interprofessional collaboration, and family member involvement in existence at an ICU. In addition, the study will develop a range of interventions aimed at enhancing such collaboration and involvement. Interventions may include but are not limited to workplace education and simulation tools, new practice guidelines, recommendations for organizational restructuration, and organizational policy.

\section{Analysis and synthesis}

In line with best practices in qualitative research, data analysis will be conducted alongside fieldwork, and fieldwork will be adapted accordingly (Seale, 1999). Factors influencing delivery of care will be analyzed using Reeves et al.'s (2010) theoretical framework and investigate relational, processual, organizational and contextual aspects of the delivery of care. Understanding how these factors facilitate or constrain interventions to improve interprofessional collaboration will be key to maximizing their potential.

After consulting with the project's advisory group, aggregated outcomes data from each ICU will be analyzed and compared across sites, as well as triangulated with qualitative data to explore any possible associations which may link the observed interprofessional processes and behaviors with the clinical outcomes produced by each participating unit.

\section{Quality issues}

Our study includes several quality checks, including iteration, member checks, accounting for negative instances/search for outliers, use of numbers, reflexivity, peer auditing and triangulation. These mechanisms are part of the best practices suggested in qualitative research literature (e.g. Mays \& Pope, 2000; Reeves et al., 2008). The research team will meet weekly to discuss observations and refine data collection techniques. Research will also be guided by an advisory committee consisting of a range of clinical and research colleagues to provide expert advice and support, most importantly during the validation process in Phase 3 , when they will be invited to provide feedback on the accuracy, usability and reliability of these tools.

\section{Discussion}

Little is known about the impact of interprofessional collaboration on the quality of care delivery in the ICU (Reeves et al., 2010). This research project has the potential to produce three important outcomes for researchers interested in this area: improving our understanding of interprofessional relations and dynamics in healthcare generally and the ICU specifically, including interactions with family members; contributing to the theory of interprofessional relations; and improving our ability to methodologically connect qualitative data and clinical outcomes. Our advisory group will be instrumental in helping us develop this connection. At the core of this project is the development of an empirically-grounded diagnostic tool to assess the efficiency and effectiveness of interprofessional collaboration in the ICU and evaluate patient/family member involvement, as well as a range of associated interventions to improve identified shortfalls. We expect to share and disseminate our findings through peerreviewed publications and conference presentations, as well as share the diagnostic tool and intervention package for broader use.

\section{Declaration of interest}

This research is funded by the Gordon and Betty Moore Foundation. The authors alone are responsible for the writing and content of the paper.

\section{References}

Bosk, C.L., Dixon-Woods, M., Goeschel, C.A., \& Pronovost, P.J. (2009). Reality check for checklists. The Lancet, 374, 444-445.

Mays, N., \& Pope, C. (2000). Qualitative research in health care: Assessing quality in qualitative research. BMJ: British Medical Journal, 320, 50-52.

Pronovost, P. (2011). Navigating adaptive challenges in quality improvement. BMJ Quality \& Safety, 20, 560-563.

Reeves, S., Kuper, A., \& Hodges, B.D. (2008). Qualitative research methodologies: Ethnography. BMJ: British Medical Journal, 337, 512 514.

Reeves, S., Lewin, S., Espin, S., \& Zwarenstein, M. (2010). Interprofessional teamwork for health and social care (Vol. 8). New York: Oxford University Press.

Rohner, R.P. (1977). Advantages of the comparative method of anthropology. Cross-cultural Research, 12, 117-144.

Seale, C. (1999). Quality in qualitative research. Qualitative Inquiry, 5, $465-478$.

Sinuff, T., Cook, D.J., \& Giacomini, M. (2007). How qualitative research can contribute to research in the intensive care unit. Journal of Critical Care, 22, 104-111.

Stevens, D.P., \& Shojania, K.G. (2011). Tell me about the context, and more. BMJ Quality \& Safety, 20, 557-559. 